\title{
OLIVIA HARRIS EN NUESTRO RECUERDO
}

\author{
Xavier Albó y Cristina Bubba
}

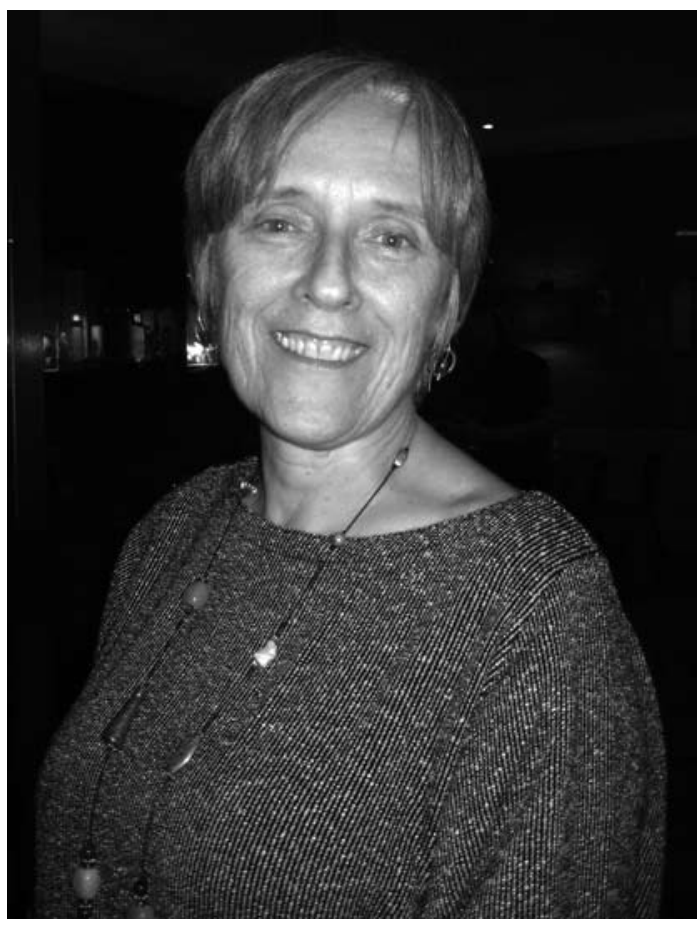

Olivia Harris, Londres, 2008.

Fotografía gentileza Frank Salomon.

La muerte de nuestra entrañable amiga Olivia Harris, acaecida el 9 de abril de 2009 en Londres, Inglaterra, ha dejado a sus parientes, amigos y a la comunidad científica muy consternados. También a los comunarios aymaras de Muruq'u Marka, en el ayllu Laymi, quienes la llamaban cariñosamente Olimpia Qhariqhari.

Nació el 26 de agosto de 1948, la cuarta de seis hermanos en una familia muy unida que ocupaba un alto rango dentro de la Corona Británica y la Iglesia Anglicana y que le brindó una educación exquisita, incluyendo poesía y una gran sensibilidad por la música, con una habilidad especial para el violín. Ya en la universidad optó primero por las lenguas clásicas e historia antigua en Oxford (1965-1969) y después por la antropología en la London School of Economics (1969-1971; Dunkerley, 2009).

Desde allí en 1972 se mudó al norte de Potosí, Bolivia, para su trabajo de campo. Le había precedido ya su compañero de carrera, Tristan Platt. Ambos, seducidos por las charlas de John Murra (Harris 2009a), el gran innovador de los estudios andinos, abrieron así una nueva brecha en esta región de Bolivia -Tristan en el ayllu Macha y Olivia en el Laymi- trascendiendo la perspectiva peruana por entonces tan dominante y completándola con las novedosas y complejas expresiones culturales que encierra todo el norte de Potosí. Más al norte, los

$1 \quad$ CIPCA, Centro de Investigación y Promoción del Campesinado. Pasaje Fabiani No. 2578. Av. 20 de Octubre/Campos y Pinilla. Casilla 5854, La Paz, Bolivia.xalbo@cipca.org.bo; xalbo@caoba.entelnet.bo

2 Fundación Illa (Saberes y Memorias), Casilla 14066, La Paz, Bolivia. cbubba@megalink.com 
historiadores franceses Thérèse Bouysse y Thierry Saignes $(\dagger 1992)$ le añadían datos y profundidad etnohistórica. Más al sur, los antropólogos chilenobolivianos Verónica Cereceda y Gabriel Martínez $(† 2000)$ le daban el toque estético, con su sensibilidad única. Ese grupo inicial fue ampliándose poco a poco con gente nueva tanto boliviana y andina como de otros varios países, que han ido renovando nuestra comprensión y compromiso con los pueblos andinos en Bolivia, Perú y el norte de Chile y Argentina.

Recién llegada, Olivia conoció a Xavier y se alojó varias veces en su casa en La Paz. Allí trabajamos juntos en su primera publicación, "Monteras y guardatojos", sobre las relaciones no siempre fluidas entre mineros y campesinos. Cristina la conoció algo después, en 1979, durante una de sus múltiples visitas al país. Nosotros y otros muchos hemos tenido la suerte de compartir con ella alegrías y penas y reflexionar sobre estos pueblos andinos.

La ascendencia familiar y la sofisticada educación británica de esta jovencita jovial, cálida, inquieta y audaz no frenaron su cercanía con la gente de las comunidades, social y culturalmente tan distinta. Se estableció en la comunidad Muruq'u Marka, a un día a pie sin camino carretero estable al sur del Distrito Minero de Catavi, en el extremo del ayllu Laymi, cerca de su conflictiva línea divisoria con los ayllus Jukumani y Qaqachaka, de habla aymara y bastantes, también con el quechua como su segunda lengua.

Treinta años después, al laymi Wilfredo Camacho le ha tocado la triste misión de ir a su ayllu y a Muruq'u Marka para avisar a su gente la muerte de Olimpia Qhariqhari. Allí ha recogido bellísimos testimonios de los propios comunarios.

Era una 'gringa' muy alta que tenía mucho entusiasmo en aprender lo que se hacia en la comunidad. Llamaba bastante la atención... una gringa que quería pastear ovejas y llamas en las frías montañas del Ayllu. Algunos comunarios de entonces se preguntaban '¿Qué quiere una gringa en la comunidad?', otros se respondían: janiy kunasa juphana utjiti, janiy kawkirusa saraña atiti, ukatay akankaskiy ukapiniy muni, khuyaqañanijay (no debe tener nada, no debe saber dónde ir, por eso debe estar aquí, eso siempre debe querer, le ayudaremos porque necesita).
Wilfredo, ahora sociólogo, resalta el uso del verbo khuyaqaña que traduce como "ayudar al que lo necesita". "Sentir compasión por el mal ajeno; tener misericordia", complementa el diccionario de Félix Layme (2004: 99). ¡Maravilloso vuelco intercultural entre la hija de refinados británicos y sus anfitriones Laymi! Ya después de su muerte, Thérèse Bouysse y Tristan Platt (2009) han descubierto una carta de Olivia a su padre escrita entonces desde allí, en la que expresa algo muy parecido desde la otra vertiente:

Dormimos en pieles de oveja tendidos sobre el suelo, cubiertos de hermosos tejidos... Estoy a medio camino del cielo... Estoy aprendiendo dos hermosos instrumentos musicales, cómo tejer y cómo cultivar papas a 13.000 pies [4.300 metros] y cómo vivir alegremente. ¿Qué más se puede pedir?

Y allí se quedó casi dos años -como nos recuerda Wilfredo- en "una pequeña habitación hecha de piedra, adobe y paja... que le cedió el ya fallecido Eusebio Inca Vilca", con quien, junto con su esposa Lidia, se hicieron compadres y le ayudaron como coinvestigadores. Sigue el testimonio de Wilfredo:

En la época de hacer chuño Olimpia estaba igualmente ayudando... Los jaqis [la gente] recuerdan que ella pisaba un buen rato el chuño y andaba casi todo el tiempo preguntando sobre muchas cosas. Después de haberse cansado ella se sentaba un momento y registraba en su cuaderno...

[En] el Tinku de Aymaya ella se presentaba bien vestida (polleras, chumpis, ajsus y demás) para ir a esta fiesta. Mi madre (Rosenda Rojas Qhariqhari) la conoció ahí... Como ellas estaba con una bandera blanca en las manos para... el baile de las jula julas... alegre con la tropa que llegaba serpenteando a la fiesta. Olimpia le preguntó a mi madre sobre su apellido, y mi madre respondió que era Qhariqhari. Enseguida Olimpia le dijo que era pariente suya porque también ella era Qhariqhari.

Durante seis meses viajó con llamas hasta los valles de Torotoro, acompañando a un prestigioso yatiri local y a su señora. Jaime Bartrolí, entonces 
párroco de Uncía, nos ha recordado también que a la hora y día menos pensados ella aparecía cansada y sonriente en su casa con su poncho, su $q^{\prime} i p i$ (bulto a la espalda) iy su violín!

Ya de retorno en Gran Bretaña, enseñó en el Goldsmiths College, de la Universidad de Londres, donde cofundó en 1986 el departamento de antropología y en la London School of Economics (LSE), donde llegó a ser decana del Departamento de Antropología entre 2005 y 2008. Fue también profesora visitante en las universidades de Chicago y de Oslo. En esos años, sin perder su interés por los Andes, se abrió a otros nuevos horizontes, como la antropología neomarxista, el género (con Kate Young, la mexicana Lourdes Arispe y el grupo Flora Tristán de Perú) y perspectivas históricas de largo aliento. Pero aquí nos concentraremos en algunos otros recuerdos más personales de su faceta andina (Bouysse y Platt 2009; Dunkerkey 2009).

Participó, junto con varios de los pioneros arriba mencionados, en el volumen Raíces de América: el Mundo Aymara (1988), que -por la crisis por la que entonces atravesaba la UNESCOapareció también parcialmente en Bolivia como Tres Ensayos sobre el Pensamiento Aymara (1987). Ella y Thérèse Bouysse, escribieron el texto clásico "Pacha, en torno al pensamiento aymara", en que nos hacen redescubrir los diversos pacha kuti, los cambios de tiempo ahora tan recordados como esperados por los pueblos andinos. En los permanentes intercambios que entonces tuvimos, era notable el cuidado y finura de los análisis de Olivia para evitar interpretaciones más llamativas y bien redondeadas pero que no acabaran de dar cuenta de realidades más complejas, que ella nunca quiso soslayar.

Aquel ejercicio todavía incipiente seguiría madurando hasta que veinte años después culminó en esa obra de romanos -o mejor, de incas- que es Qaraqara-Charka, un esfuerzo que había sido concebido ya en 1982 en Sucre por Olivia, Tristan, Thérèse y Thierry, bajo la mirada de Gunnar Mendoza (Bouysse y Platt 2009), y finalmente presentado allí mismo en 2006 durante el IV Encuentro de Estudios Bolivianos. No era fácil colocar semejante volumen de 1.088 páginas. Pero al año ya se había agotado. En 2006 ella misma nos lo entregó, con su firma "Olivia/Aceituna" -el apodo cariñoso que aquí le dábamos-, cuando coincidimos los tres en el aeropuerto de La Paz. Para Cristina, fue la última vez que se vieron. Xavier tuvo todavía la dicha de alojarse en su casa en Londres y charlar horas paseando por un parque cercano en 2008.

Aparte del largo ensayo interpretativo inicial y las otras seis presentaciones temáticas, el cuerpo del volumen lo forman 22 documentos que nos permiten entender mejor la perspectiva andina desde diversos ángulos. A ello se unen numerosas láminas, figuras, cuadros y mapas. Estos últimos reflejan la temprana afición que tanto Olivia como los otros coautores, incluido Thierry Saignes, siempre tuvieron por ellos, dándonos una fresca visión de las concepciones del espacio que estos pueblos tienen y tuvieron. Olivia lo expresó además en un hermoso artículo sobre el tema en el libro homenaje a este brillante investigador y amigo (Harris 1997). Por el documento 16 de Qaraqara-Charka (2006:72-74, 734-735, 741) sabemos incluso de "mapas" tejidos en ropa de cumbi (qumpi), que los naturales llaman Carpatira. ¡Cuántos misterios ocultarán todavía esos tejidos andinos!

Dar profundidad histórica a los datos etnográficos siempre fue algo central en el trabajo de Olivia y su grupo de trabajo. Había contribuido ya a ello su previa formación clásica pero lo que más les marcó fue su temprana vinculación con John Murra. En el obituario que ella misma escribió para John Murra (The Guardian, noviembre de 2006; Harris 2009b) resalta que su maestro nunca se alineó con "la cosmología exótica" sino que partía de "la pregunta mucho más pragmática sobre cómo se organizaba esta sociedad única" (citado en Dunkerley 2009). Olivia adoptó también esta misma perspectiva en todo su trabajo, más orientado a comprender los procesos del pasado hacia el presente.

Por eso otro de sus intereses centrales fue, naturalmente, el de la economía, que en los Andes va tan asociada a la ecología (recordemos los célebres "archipiélagos" y "nichos ecólógicos" de Murra 1975) $\mathrm{y}$, a la vez, a la cosmovisión religiosa. Estas pistas de búsqueda de Olivia aparecen desde sus ensayos más tempranos, reproducidos en parte en el librito popular Economía Étnica (1987) editado en La Paz por su amigo Javier Medina, hasta la antología de ensayos que años después publicó en Londres To Make the Earth Bear Fruit (2000). Con los años aquel interés se fue expandiendo también hacia el tema de los circuitos comerciales andinos, que ya va mucho más allá de los pisos ecológicos, y que -bajo su batuta, la de Enrique Tandeter $(†$ 2004) y la de Brooke Larson-fue objeto de tres eventos internacionales patrocinados por el Social Science 
Research Council en Inglaterra, Bolivia y Estados Unidos.

Esos temas no podían desligarse de la cosmovisión ni de las formas específicas de los saberes andinos, en los que Olivia se adentró sobre todo a través de su cuidadoso trabajo etnográfico. Resaltaba que el pueblo andino, como tantos otros, funciona con sus propios sistemas de conocimiento y expresión poco reconocidos por las ideologías y sistemas educativos dominantes. Tal es el caso del yatiri, con su capacidad de entender a partir de su propia experiencia y su arte para leer hojas de coca y comunicarse con los seres del mundo de adentro y del complejo sistema de protectores en las pampas y las montañas (Harris 1995). Percibió a diario cómo todo ese otro universo, que abarca también el mundo de los muertos, sigue para los Laymi siempre muy vivo e interactuante (Harris 1983).

Estos son apenas algunos de los temas y ámbitos en que se movió Olivia. Coincidimos con tantos que estos días han escrito sobre ella, en que es todavía demasiado temprano para poder valorar de manera cabal la influencia de todo su trabajo, hoy truncado por su temprana muerte. No pudo culminar, por ejemplo, la tarea en que últimamente estaba más embarcada, a saber, "mi libro sobre los Laymi y otros" (carta a Cristina, 10-IX-2008).

Pero, cerrando nuestra rememoración, lo que de Olivia sigue llenándonos más es su perfil humano y cálido, esbozado ya en aquellos recuerdos de sus primeros años en Bolivia y que mantuvo en todos esos años hasta los días mismos de su muerte, bien acompañada de Harry Lubasz, su querido esposo, y Marina, su tan buscada y querida hija anglo-boliviana-aymara.

Pocos años después de su paso por Muruq'u Marka, su compadre y coinvestigador Eusebio falleció prematuramente, a sus 35 años, por descuido de atención en un hospital local. Mucho le dolió y preocupó a Olivia. Poco pensaría entonces que, transcurridos los años y a pesar de los impecables cuidados del sistema médico británico, la muerte también la asaltaría a ella de una manera igualmente brutal. Ahora los dos se han reencontrado de nuevo en la otra vertiente de la vida. Los propios Laymis le enseñaron a aceptar con esperanza ese misterio por el que tarde o temprano todos transitamos. Lo mismo piensa su "paisano" laymi Wilfredo:

Olimpia seguramente ha estado en estas últimas semanas por los caminos accidentados y los lugares que ella frecuentaba en los ayllus del norte de Potosí, visitando probablemente a los comunarios y comunarias de los Laymi. Olimpia estará siempre inscrita en [su] la memoria... Desde su desaparición Olimpia volvió a nuestra comunidad y camina entre nosotros, y está protegida ahora por los achachilas y kumpiras [cumbreras].

Que las cumbres mallku te sigan protegiendo, querida Olivia, y que sigas cerca de todos nosotros siempre alegre, cantando, bailando y tocando el violín.

\section{Referencias Citadas}

Bouysse-Cassagne, T. y T. Platt

2009 Obituario. Olivia Harris (1948 - 2009), Catedrática de Antropología en la London School of Economics. T'inkazos 26:139-146.

Camacho, W.

2009 Olivia Harris en la memoria de los comunarios. Manuscrito en poder del autor.

Dunkerley, J.

2009 Obituary, Olivia Harris. Anthropologist notable for outstanding work in Bolivia's highlands. The Guardian (London) 20-IV- 2009.

Layme, F.

2004 Diccionario Bilingüe Aymara Castellano. Consejo Educativo Aymara, La Paz.

Harris, O.

1983 Los muertos y los diablos entre los laymi de Bolivia. Chungara 11:135-152.
1986 Economía Étnica. Hisbol, La Paz. Breve Biblioteca de Bolsillo, n. 3.

1987 Los límites como problema: Mapas etnohistóricos de los Andes bolivianos. En Saberes y Memorias en los Andes. In Memoriam de Thierry Saignes, editado por T. BouysseCassagne, pp. 351-573. CREDAL-IFEA, Paris-Lima.

1995 Knowing the past: Plural identities and the antinomies of loss in Highland Bolivia. En Counterworks. Managing the Diversity of Knowledges, editado por R. Fardon, pp. 108-126. Routledge, London.

2000 To Make the Earth Bear Fruit: Ethnographic Essays on Fertility, Work and Gender in Highland Bolivia. Institute of Latin American Studies, University of London, London. 2009a "Trocaban el trabajo en fiesta y regocijo". Acerca del valor del trabajo en los andes históricos y contemporáneos. Chungara Revista de Antropología Chilena Vol. 41 Número Especial Homenaje a John Murra, en preparación. 
2009b Murra 1916-2006. Chungara Revista de Antropología Chilena Vol. 41 Número Especial Homenaje a John Murra, en preparación.

Harris, O. y X. Albó

1976 Monteras y Guardatojos: Campesinos y Mineros en el Norte de Potosí. CIPCA, La Paz.

Harris, O. y T. Bouysse-Cassagne

1988 Pacha: en torno al pensamiento aymara. Raíces de América: el mundo aymara, compilado por X. Albó, pp. 217-274. Alianza Editorial y UNESCO, Madrid. (Reproducido también en Tres Reflexiones sobre el Pensamiento Andino, editado por T. Bouysse-Cassagne,
O. Harris, T. Platt y V. Cereceda. Hisbol, La Paz, 1987).

Harris, O., B. Larson y E. Tandeter, editores 1987 Participación Indígena en los Mercados Surandinos. CERES, La Paz. (Versión inglesa: Duke University Press, 1995).' Murra, J.V.

1975 Formaciones Económicas y Políticas en el Mundo Andino. IEP, Lima.

Platt, T., T. Bouysse Cassagne y O. Harris 2006 Qaraqara-Charka: Mallku, Inka y Rey en la Provincia de Charcas (Siglos XV-XVII), con el aliento de Thierry Saignes. IFEA-Plural, La Paz. 
